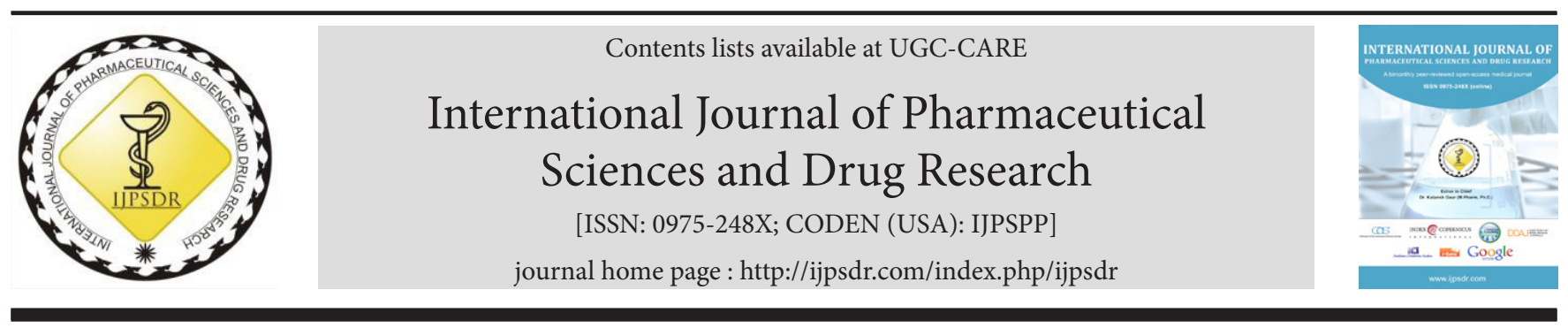

Research Article

\title{
Green Reactants Act as a Natural Precursor for Facile Synthesis of Nanoparticles using Withania somnifera
}

\author{
Rajeswari Anburaj* \\ Department of Microbiology, Nadar Saraswathi College of Arts and Science, Theni-625531, Tamil Nadu, India
}

\author{
A RT ICLE INFO \\ Article history: \\ Received: 26 December, 2019 \\ Revised: 25 February, 2020 \\ Accepted: 10 March, 2020 \\ Published: 30 March, 2020 \\ Keywords: \\ Biofabrication, Biofunctional, \\ Biocidal. Phytonanotechnology, \\ Silver ions. \\ DOI: \\ 10.25004/IJPSDR.2020.120202
}

\begin{abstract}
A B S T R A C T
Nanotechnology includes physical and chemical approaches intended for their phytofabrication of metal nanoparticles. Most of the time, these methods are not as safe as these are associated with the utilization of extremely noxious and hazardous substances that produce biological problems. Due to their manifold applications, various biological methods are gaining admiration for the fabrication of silver nanoparticles (AgNPs). The utilization of vegetative parts in the biosynthesis of nanoparticles (NPs) emerges as a commercial and ecological approach. The spectroscopic profile confirms the occurrence of a functional peak at $360 \mathrm{~nm}$. Fourier transform infrared spectroscopy (FTIR) studies indicate that phenol groups are responsible for phytofabrication of NPs. The results of microbicidal screening confirm that broad spectrum of inhibition was found to be observed in $400 \mu \mathrm{L}$ of biosynthesized AgNP against E. coli $(23 \mathrm{~mm})$ and $B$. cereus $(22.3 \mathrm{~mm}$ ) Therefore, the progress of simple photosynthesis methods avoid deleterious and harmful properties has fascinated major attention in this field.
\end{abstract}

\section{INTRODUCTION}

Nanotechnology is the science of manipulation of nanomaterials with various properties used to make novel devices. ${ }^{[1]}$ Conventional approaches in the synthesis of AgNPs include physical and chemical methods. ${ }^{[2]}$ Apart from these methods, lethal and hazardous substances implicated in the phytosynthesis acquire various biological risks and are accountable for enormous health problems. A variety of biological agents act as in vitro reducing and capping agents (plant and microbial derivatives) are responsible for bioreduction. These methods are own for the production of various nanomaterials like gold, silver, zinc, copper, iron, etc. ${ }^{[3,4]}$ In the field of medical microbiology, disease diagnosis ${ }^{[5]}$ is facilitated with the aid of gold nanomaterials. Nanoparticle comes in contact with membrane structure, damages the membrane permeability by means of depolarization. Silver ions attach to proteins present in tissue and finally leads to disruption of cell integrity and death. ${ }^{[6-8]}$

Superior cytotoxicity against bacteria is brought about by the amalgamation of diverse compounds such as antibiotics, AgNP complexes, with enhanced properties of their active surfaces. ${ }^{[9]}$ Nanomaterials are produced mechanically by electro-spinning process, which encourages biocidal properties and biocompatibility with human cells. ${ }^{[10]}$ The permeability in membrane allows small-sized AgNPs to accumulate in the internal membrane of the cell. ${ }^{[11]}$ NPs counter against the eukaryotic cells by means of phagocytosis and endocytosis. ${ }^{[12]}$ The mechanism depends on the prescribed quantity with cytotoxicity effects. ${ }^{[11]}$ AgNPs come in contact with the plasma membrane and discharge $\mathrm{Ag}^{+}$ions into cytoplasm, followed by the ion exchange mechanism,

\footnotetext{
*Corresponding Author: Mrs. Rajeswari Anburaj

Address: Department of Microbiology, Nadar Saraswathi College of Arts and Science, Theni-625531, Tamil Nadu, India

Email $₫$ : raji.anburaj@gmail.com

Tel.: +91-9043835023
}

Relevant conflicts of interest/financial disclosures: The authors declare that the research was conducted in the absence of any commercial or financial relationships that could be construed as a potential conflict of interest.

Copyright (C) 2020 Rajeswari Anburaj, This is an open access article distributed under the terms of the Creative Commons Attribution- NonCommercialShareAlike 4.0 International License which allows others to remix, tweak, and build upon the work non-commercially, as long as the author is credited and the new creations are licensed under the identical terms. 
and blocks the synthesis of sulfur-containing proteins on ribosomes. ${ }^{[13]}$

Withania somnifera $L$. is a medicinal plant with essential phytoconstituents belonging to the Solanaceae family, commonly known as red ginseng, ashwagandha, withanolides that contribute to most of the biological activity of $W$. somnifera. ${ }^{[14]}$ Leaves of the plant is rich in biochemical compounds such as alkaloids, steroidal lactones, tannin, etc. ${ }^{[15]}$ Vegetative parts of leaves are enriched with more than 12 alkaloids, 40 withanolides containing a glucose molecule at carbon. In leaves, the concentration of withanolides usually ranges from 0.001 to $0.5 \%$ dry weight. ${ }^{[16]}$ The pharmacological properties of this plant are due to Anolides, a combination of steroidal lactones found in the leaves of this plant. ${ }^{[17]}$ The Withania somnifera extract, when administered orally, prevented the increase in LPO levels. ${ }^{[18-20]}$ These biosynthesized compounds are believed to manipulate the mechanism in the cortical and basal forebrain cholinergic-signal transduction cascade. ${ }^{[19]}$ Thus, W. somnifera contains bioreduction agents such as terpenoids, flavonoids, proteins, and alkaloids, which initiate the synthesis of nanoparticles. ${ }^{[21]}$

In the present investigation, biofabrication of AgNPs using Withania sominfera was examined. The optimization of phytofabricated AgNP was done to indicate the presence of nanoparticles. Bioefficacy of AgNP was using microbicidal assay, and characterization was confirmed using FTIR, scanning electron microscopy (SEM), energy dispersive X-ray (EDX), and dynamic light scattering (DLS) analysis.

\section{Materials AND METhods}

\section{Plant Materials}

Leaf samples of Withania somnifera were selected for the study. The leaves were immersed in running water, desiccated under shade conditions, and homogenized using an electrical blender. The obtained leaf samples were stored and used for further studies.

\section{Phytochemical Analysis}

Plant materials were assessed for the occurrence of various biologically active compounds like flavonoids, alkaloids, glycosides, steroids, phenols, saponins, and tannins due to the methods proposed by Harborne et al. ${ }^{[22]}$

\section{Characterization of Phytoassisted Silver Nanoparticles}

The major shift in the optical color of the solution to dark brown accounts for the complete bioreduction of $\mathrm{Ag}^{+}$, overnight samples of synthesized AgNPs were measured using UV-2550 Shimadzu Spectrophotometer (Shimadzu Corporation, Kyoto, Japan). The rapidly formed biosynthesized AgNPs were obtained by centrifugation at $10,000 \mathrm{rpm}$ for 10 minutes in a centrifuge and carefully washed with sterile $\mathrm{ddH}_{2} \mathrm{O}$, and freeze-dried and stored at $-80^{\circ} \mathrm{C}$. Based on the fast reduction of $\mathrm{AgNO}_{3}$ into $\mathrm{AgNPs}$, the capable AgNPs sample prepared from $15 \mathrm{~mL}$ of fruit extract was used for further characterization using several methods, including UV-visible spectroscopy, FTIR, SEM, EDX spectroscopy, and diffraction light scattering analysis.

\section{UV-vis Spectroscopy}

Visual examination of the phytosynthesized AgNP has experimented for any color change, and $1 \mathrm{~mL}$ of the combined mixture was withdrawn successively at different time levels by diluting a small aliquot $(100 \mu \mathrm{L})$ of the reactant sample 10 -fold in deionized water for the study of surface plasmon resonance of silver nanoparticles. The reduction process of pure $\mathrm{Ag}^{+}$ions was evaluated by using a UV-vis spectrophotometer (Shimadzu 1601 model, Japan) at the resolution of $1 \mathrm{~nm}$ in the range of 200-800 $\mathrm{nm}$.

\section{Fourier Transform Infrared Spectroscopy Analysis}

The functional assignments of the NPs were qualitatively confirmed by using FTIR spectroscopy ${ }^{[23]}$ with spectra recorded by a Perkin-Elmer Spectrum 2000 FTIR spectrophotometer. Shimadzu FT-IR model number 8400 was used to perform FTIR analysis. A $3 \mathrm{mg}$ of powdered leaf samples was mixed with $300 \mathrm{mg}$ of dried $\mathrm{KBr}$, and thin pellets were prepared for analysis of the sample. A similar process was carried out for phytosynthesised AgNPs using an extract. Scanning of samples was performed in a range of $400-4000 \mathrm{~cm}^{-1}$.

\section{Scanning Electron Microscopy (SEM)}

The SEM with an ultra-high-resolution is used for detecting the arrangement and composition of purified AgNPs, analyzed by using a $10-\mathrm{kV}$. A mixture of purified silver nanomaterials was obtained after repetitive centrifugation, carbon-coated copper grids were used for sputter coating, and imagery descriptions of nanoparticles were analyzed by FEI QUANTA-200 SEM.

\section{Dynamic Light Scattering (DLS)}

Dynamic light scattering (DLS) was used in analyzing the size distribution pattern of the biofabricated AgNPs, Model DLS (Malvern, UK). In this experimental analysis, 0.15 M PBS (pH 7.4) was used to dilute the samples, 10-fold dilution was done and the dimensions were recorded in the range between 0.1 and $10,000 \mathrm{~nm}$.

\section{Microbicidal Screening of Phytosynthesised AgNPs}

Antimicrobial activity of synthesized AgNPs was evaluated against the pathogen such as Bacillus sp., Escherichia coli, Mycobacterium mucilaginosus, Klebsiella terrigena, Pseudomonas aeruoginosa, Shigella, Staphylococcus epidermis, Fusarium oxysporum, Penicillium, Aspergillus 
niger by Kirby Bauer method as experimented by Elbeshehy et al. ${ }^{[24]}$ Overnight culture was maintained in LB broth at $30^{\circ} \mathrm{C}$ (approximately $\sim 1 \times 10^{8} \mathrm{CFU} / \mathrm{mL}$ ), lawn culture was done with $5 \mathrm{~mL}$ of LB agar medium on the LB agar medium. Incubation of fungal cultures was done at $25^{\circ} \mathrm{C}$ for 48 hours, inoculated into potato dextrose broth and was spread in potato dextrose agar medium. After drying of the agar medium, $40 \mu \mathrm{L}$ of the concentration of AgNPs were loaded at the equivalent space on agar well (6 $\mathrm{mm}$ ) and grown for 24 hours at $30^{\circ} \mathrm{C}$. A similar quantity of filter-sterilized leaf extract was used as a control. The microbicidal activity was determined by averaging the diameter of the inhibition zone. To determine the activity, the diameter of the inhibition zone was measured around the whole. Three repeated experiments has been done for antimicrobial evaluation.

\section{RESULTS AND DiscusSion}

\section{Phytochemical Investigation of Withania somnifera}

The results of bioactive constituents of plant samples were summarized in Table 1 . The plant samples were subjected to phytochemical analysis by extracting with various solvents. Acetone and aqueous extract displayed positive results towards the majority of compounds except for saponin and terpenoid. Ethanol and methanol extract possess alkaloid, flavonoid, phenol, and glycosides extract, whereas hexane extract displayed negative results towards the majority of compounds except for steroids. The flavonoids and terpenoids are the biomolecules present in the leaves of $W$. somnifera act as a bioreductant which are responsible for conversion of silver nitrate into silver ions. ${ }^{[25]}$

\section{Spectroscopic Profile of Plant Assisted AgNPs}

\section{Optimization Factors in Photosynthesis of AgNPs}

Spectroscopic profile of plant assisted AgNPs were represented in Fig. 1-4. Various biosynthesis of fabricated AgNPs have been documented using vegetative parts from, Lippia nodiflora. ${ }^{[26]}$ Diverse factors such as time, $\mathrm{pH}$, temperature, and concentration of $\mathrm{AgNO}_{3}$ were evaluated for the optimization of biosynthesis of AgNPs.
The visual changes experimented could be recognized due to the spectroscopic peaks. ${ }^{[27]}$ The range and shape of nanomaterials influence the biological properties. ${ }^{[28]}$ In the existing study, the biosynthesized AgNPs at $70^{\circ} \mathrm{C}$, shows a broader peak at $360 \mathrm{~nm}$. The amplification of nanoparticles is enhanced by the visual intensity of solution obtained by the bioreduction process.

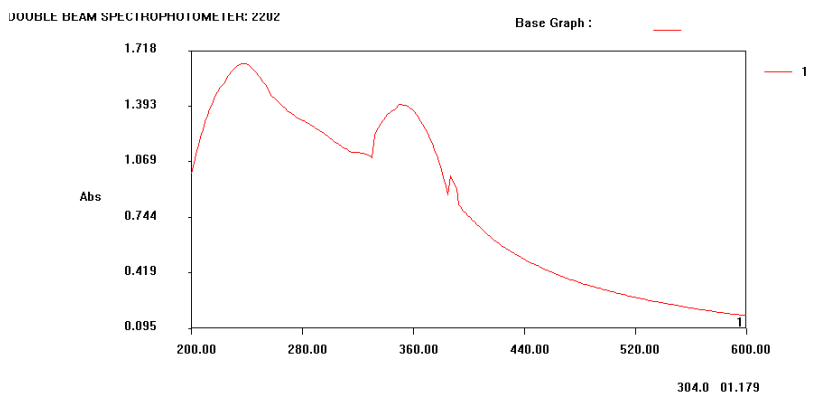

Fig. 1: Experimental analysis of biofabricated NPs at $70^{\circ} \mathrm{C}$

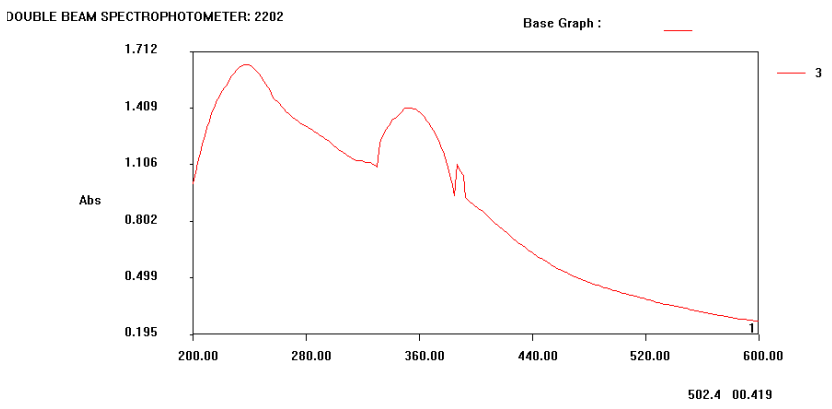

Fig. 2: Experimental analysis of biofabricated NPs at 2 hours

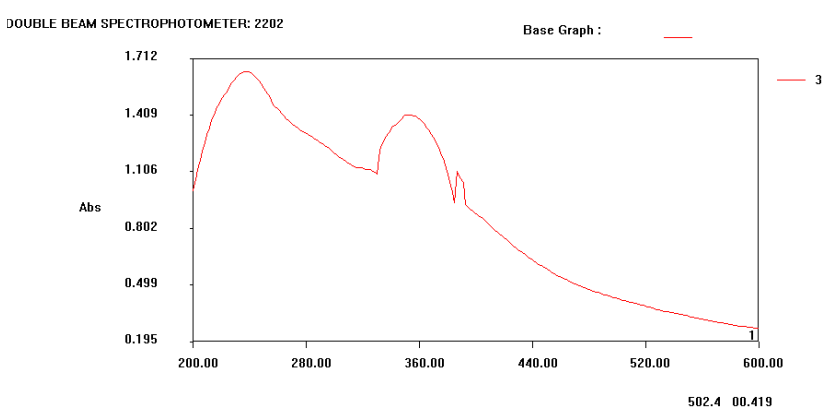

Fig. 3: Experimental analysis of biofabricated NPs at $\mathrm{pH} 4$

Table 1: Bioactive constituents in Withania somnifera

\begin{tabular}{llllllll}
\hline Phytoconstituents & $A$ & $E$ & $E A$ & $M$ & $P E$ & $H$ & $W$ \\
\hline Alkaloid & + & + & - & + & + & - & + \\
Flavanoid & + & + & + & + & - & - & + \\
Saponin & - & - & - & + & - & - & + \\
Tannin & + & - & - & - & - & - & + \\
Phenol & + & + & + & + & + & - & + \\
Glycosides & + & + & + & + & - & - & + \\
Terpenoid & + & - & - & + & + & - & - \\
Steroid & + & - & - & - & - & + & + \\
\hline
\end{tabular}

A - Acetone; E - Ethanol; EA - Ethyl acetate; M - Methanol; P - Petroleum ether; H - Hexane; W - Water

*The results are triplicates of the samples 


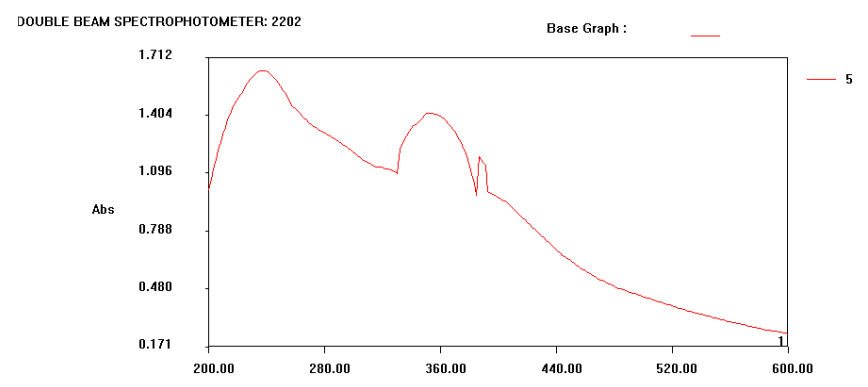

Fig. 4: Experimental analysis of biofabricated NPs at $2 \mathrm{mM}$

UV spectrum of plant synthesized AgNPs possess an elevated peak at 2 hours. Electrostatic interactions flanked by the $\mathrm{Ag}^{+}$ions and proteins in $W$. somnifera are responsible for the bioreduction of Ag. In the present study, the UV-Vis spectrum obtained elevated levels of peak at $\mathrm{pH}$ 4. Positively charged photosynthesized NPs interact with cell surface of bacteria, which is negatively charged, this reductant reaction occurs at a low $\mathrm{pH}$ level. ${ }^{[29]}$ Proteins are capable of reducing silver ion and play a vital role in the formation of silver nuclei. The produced silver nuclei are sequentially developed by the bioreduction of Ag ions and formation of nuclei, which is the primary factor in the formation of AgNPs. ${ }^{[30]}$ In the existing investigation, the AgNPs synthesized at $2 \mathrm{mM}$ concentration was found to be effective in producing a broader spectrum. The increase in maximum absorbance at different concentrations is due to the particle density, which strongly depends on the amount of silver reduction at the surface of the medium. ${ }^{[31]}$

The FTIR spectrum of biosynthesized AgNPs was depicted in Fig. 5. The absorption of various functional assignments like $\mathrm{O}$-stretching of phenol and alcohol, the group of $\mathrm{N}-\mathrm{H}, \mathrm{O}-\mathrm{H}, \mathrm{C}=\mathrm{O}$, the phytol compounds of amino acids, and proteins are said to be implicated in the process of biofabricated NPs. ${ }^{[32]}$ The functional assignments at $3430 \mathrm{~cm}^{-1}$ correspond to $\mathrm{O}-\mathrm{H}$ stretching vibration. Previous studies reported that $\mathrm{O}-\mathrm{H}$ stretching vibrations of the phenol group are responsible for the reduction

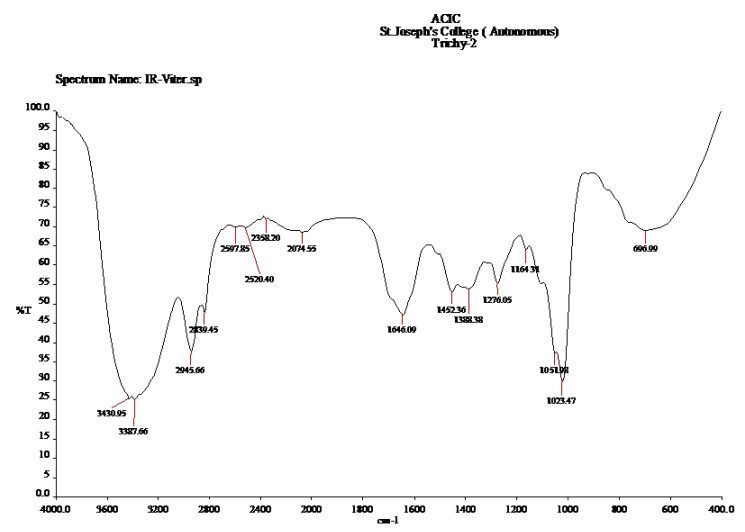

Fig. 5: Functional assignments of phytofabricated AgNPs and capping of nanomaterials. ${ }^{[33]}$ The absorption peak at $2945 \mathrm{~cm}^{-1}$ belongs to $\mathrm{CeH}$ stretching, the peak at $1646 \mathrm{~cm}^{-1}$ is responsible for amide groups, and the results corroborated with previous reports. The absorption peaks at $3420 \mathrm{~cm}^{-1}$ was responsible for -OH group, followed by the region at $2920 \mathrm{~cm}^{-1}$ corresponds to $\mathrm{CeH}$ stretching. Absorbance peak at $1606 \mathrm{~cm}^{-1}$ indicates the presence of proteins by the amine or amide I group. Also, the peak at $1606 \mathrm{~cm}^{-1}$ was appended by AgNPs with the C-O functional groups. ${ }^{[34]}$ In the previous reports, the functional assignments at $2921 \mathrm{~cm}^{-1}$ confirm the existence of $\mathrm{C}-\mathrm{H}$ group of an aromatic compound. ${ }^{[35]}$

In the existing study, the wavenumber at $1452 \mathrm{~cm}^{-1}$ indicates the aromatic group, followed by the absorption spectrum at $1023.47 \mathrm{~cm}^{-1}$ belongs to the secondary AOH group, the FTIR spectrum was correlated with prior studies. The peak at $1408 \mathrm{~cm}^{-1}$ belongs to the OAH bend of polyphenol corresponds to an aromatic group, whereas the peaks at $1013 \mathrm{~cm}^{-1}$ indicate the occurrence of CAOAC and secondary $\mathrm{AOH}$ group ${ }^{[36,37]}$ of plant extract. The wavenumber at $696 \mathrm{~cm}^{-1}$ might be due to the presence of alkyl halides, confirmed by the preceding studies. The functional groups at $699 \mathrm{~cm}^{-1}$ and $504 \mathrm{~cm}^{-1}$ corresponds to alkyl halides stretching. ${ }^{[38]}$ The assignments at $2074.55 \mathrm{~cm}^{-1}$ indicate the occurrence of alkyne groups, and the band at $1646.09 \mathrm{~cm}^{-1}$ is responsible for $\mathrm{C}=0$ peak. The results correlated with the biosynthesis of NPs obtained from previous reports. ${ }^{[39]}$ The peaks at 1388.38 $\mathrm{cm}^{-1}$ correspond to $\mathrm{C}-\mathrm{N}$ stretch vibrations and the amide I bands of proteins in the extract. ${ }^{[40]}$ The FTIR studies prove that the carbonyl groups of amino acids and peptides of proteins to attach to the surface of metal ions and play an essential role in forming a protective coat around the nanoparticles, which helps in stabilization of the medium.

\section{Scanning Images of Bio Fabricated AgNPs using FE-SEM}

The SEM images of plant assisted AgNPs were represented in Fig. 6. The SEM determines distribution of biosynthesized AgNPs at the nanoscale, a surface analyzing technique, used to identify diverse particle shapes, morphology, range. ${ }^{[39]}$ In the existing study, images of biofabricated AgNPs was found to be spherical and uniformly distributed, biofabricated NPs that have carbonyl, primary amine group correlated with prior reports.

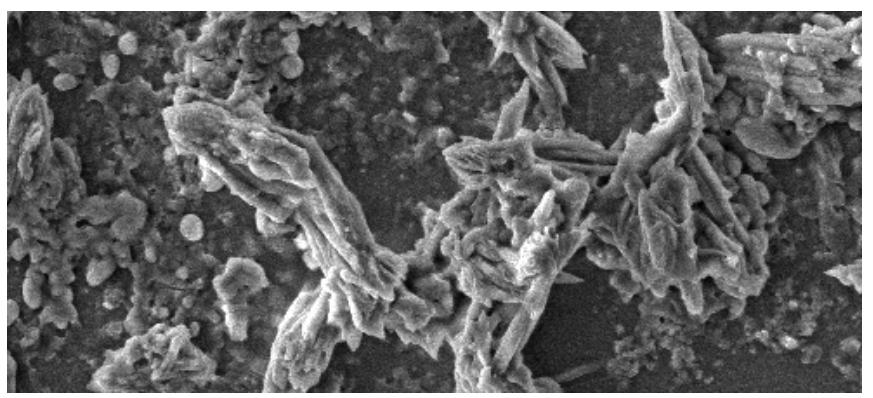

Fig. 6: FE-SEM micrograph of photosynthesized AgNPs 


\section{EDX Spectrum of Phytofabricated AgNPs}

The EDS profile exhibited the presence of silver along with some peaks were depicted in Figs. 7 and 8. The peaks may be attributed due to the presence of bioactive constituents that are attached to the exterior surface of AgNPs, signifying the bioreduction process.

\section{Dynamic Light Scattering Study}

The DLS profile of phytofabricated AgNP was represented in Fig. 9. This is due to the experimentation of small particles ${ }^{[41-43]}$ as well as the existence of unreacted extract indicates the occurrence of the AgNPs. The hydrodynamic analysis of the distribution reveals that the size of AgNps is $100 \mathrm{~nm}$.

\section{In vitro Microbicidal Assessment of W. somnifera}

In vitro microbicidal assay of plant extract was tested against various pathogens using well diffusion technique (Table 2). Antibiotic resistance possesses serious hazard to human wellbeing. Therefore, there is an increase in the investigation of vegetative parts as a source for the management of the infectious disease. ${ }^{[44,45]}$ Among the extracts assayed methanol extract possess maximum inhibitory effect against $E$. coli $(22.3 \mathrm{~mm}), B$. cereus (21 $\mathrm{mm})$, S. aureus $(20.4 \mathrm{~mm})$, followed by acetone extract $(22,20.5$, and $19.6 \mathrm{~mm})$. The inhibitory effect was found to be moderate in ethanol extract against $K$. pneumoniae $(16.5 \mathrm{~mm})$ and $M$. mucilaginosus $(14.3 \mathrm{~mm})$, followed by chloroform extract against M. mucilaginosus (13.4 mm). The level of inhibition was found to be minimum in

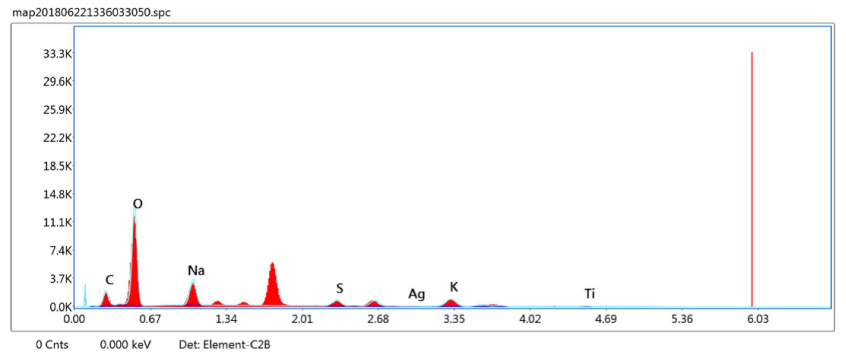

Fig. 7: Electrodiagnostic spectrum of phytofabricated AgNPs petroleum ether extract against $K$. terrigena $(14 \mathrm{~mm})$ and M. mucilaginosus (12.5 mm).

Methanol extract possess maximum fungicidal effect against $A$. niger $(19.7 \mathrm{~mm})$, followed by Penicillium $(18.5 \mathrm{~mm})$ and $F$. oxysporum $(17.4 \mathrm{~mm})$, followed by acetone extract $(18.5,17.3$, and $16.3 \mathrm{~mm})$. Chloroform

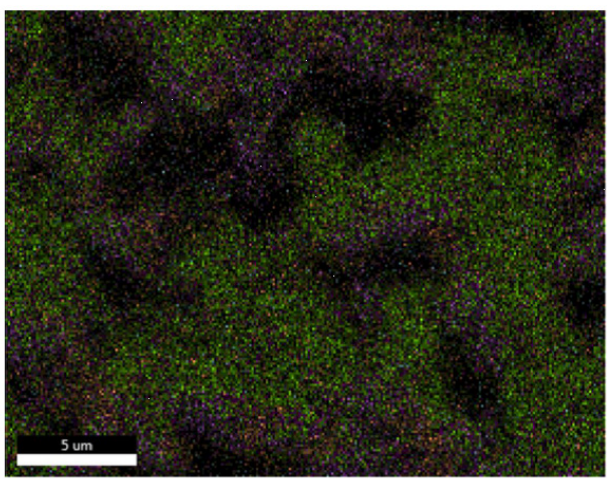

$8 \%$ с K

$54 \%$ о $\mathrm{K}$

$19 \%$ NaK

$6 \% \mathrm{sK}$

$1 \% \mathrm{AgL}$

$9 \%$ к к

$1 \%$ тік

\section{Intensity Distribution}

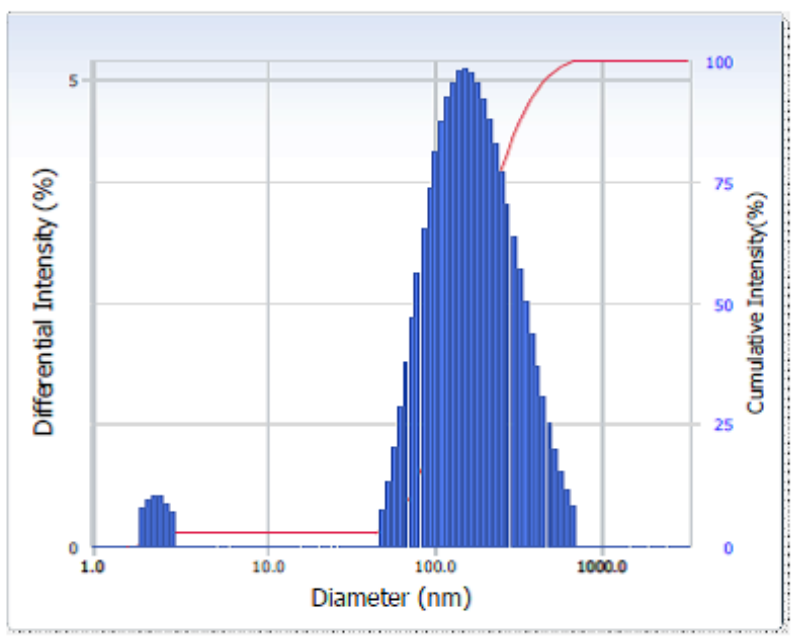

Fig. 9: DLS spectrum of biofabricated AgNPs

Table 2: Microbicidal assessment in Withania somnifera

\begin{tabular}{|c|c|c|c|c|c|c|}
\hline \multirow[b]{2}{*}{ S. No. } & \multirow[b]{2}{*}{ Microorganism } & \multicolumn{5}{|c|}{ Withania somnifera } \\
\hline & & Acetone & Chloroform & Ethanol & Methanol & Petroleum ether \\
\hline 1. & Bacillus cereus & $20.5 \pm 0$ & $19.7 \pm 0.1$ & $19.4 \pm 0.2$ & $21 \pm 0$ & $18.7 \pm 0.1$ \\
\hline 2. & Klebsiella pneumonia & $17.7 \pm 0.1$ & $15.6 \pm 0$ & $16.5 \pm 0.1$ & $18.7 \pm 0.1$ & $14.6 \pm 0.2$ \\
\hline 3. & Pseudomonas aeuroginosa & $18.1 \pm 0$ & $16.5 \pm 0$ & $17.5 \pm 0$ & $19.3 \pm 0.2$ & $16 \pm 0$ \\
\hline 4. & Staphylococcus aureus & $19.6 \pm 0$ & $18 \pm 0$ & $18.7 \pm 0.1$ & $20.4 \pm 0.2$ & $17.2 \pm 0.2$ \\
\hline 5. & Escherichia coli & $22 \pm 0$ & $20.6 \pm 0.1$ & $21.5 \pm 0$ & $22.3 \pm 0.1$ & $19.6 \pm 0.1$ \\
\hline 6. & Mycobacterium mucliaginosus & $15.3 \pm 0.1$ & $13.4 \pm 0.2$ & $14.3 \pm 0.1$ & $15.6 \pm 0.1$ & $12.5 \pm 0$ \\
\hline 7. & Klebsiella terrigena & $16.7 \pm 0.1$ & $14 \pm 0$ & $15 \pm 0$ & $16.4 \pm 0.2$ & $14 \pm 0$ \\
\hline 8. & Fusarium oxysporum & $16.3 \pm 0.2$ & $14.7 \pm 0.1$ & $16.5 \pm 0$ & $17.4 \pm 0.1$ & $12.6 \pm 0.1$ \\
\hline 9. & Penicillium & $17.3 \pm 0.2$ & $15 \pm 0$ & $17.7 \pm 0.1$ & $18.5 \pm 0$ & $13.6 \pm 0.1$ \\
\hline 10. & Aspergillus niger & $18.5 \pm 0$ & $17.4 \pm 0.1$ & $18.5 \pm 0$ & $19.7 \pm 0.1$ & $15 \pm 0$ \\
\hline
\end{tabular}

*Values are mean of \pm S.D, $n=3$ 
Rajeswari Anburaj

Table 3: Microbicidal screening of phytofabricated AgNPs using Withania somnifera

\begin{tabular}{|c|c|c|c|c|c|c|}
\hline \multirow[b]{2}{*}{ S. No. } & \multirow[b]{2}{*}{ Microorganism } & \multicolumn{5}{|c|}{ Withania somnifera } \\
\hline & & $100 \mu L$ & $200 \mu L$ & $300 \mu L$ & $400 \mu L$ & $250 \mu \mathrm{L} \mathrm{AgNP}$ \\
\hline 1. & Bacillus cereus & $19.3 \pm 0.1$ & $20 \pm 0$ & $21.5 \pm 0.1$ & $22.3 \pm 0.1$ & $23.5 \pm 0$ \\
\hline 2. & Klebsiella pneumonia & $16.4 \pm 0.1$ & $16.5 \pm 0.1$ & $18 \pm 0$ & $19.7 \pm 0.2$ & $20.5 \pm 0$ \\
\hline 3. & Pseudomonas aeuroginosa & $17.5 \pm 0$ & $18.4 \pm 0.2$ & $19.2 \pm 0.1$ & $20.7 \pm 0.1$ & $21 \pm 0$ \\
\hline 4. & Staphylococcus aureus & $18.3 \pm 0.1$ & $19.4 \pm 0.1$ & $20.5 \pm 0$ & $21.3 \pm 0.2$ & $22.3 \pm 0.1$ \\
\hline 5. & Escherichia coli & $20.5 \pm 0$ & $21.2 \pm 0.2$ & $22.3 \pm 0.1$ & $23 \pm 0$ & $24.3 \pm 0.1$ \\
\hline 6. & Mycobacterium mucliaginosus & $14.1 \pm 0.1$ & $15.5 \pm 0$ & $16.6 \pm 0$ & $17.2 \pm 0.2$ & $18 \pm 0$ \\
\hline 7. & Klebsiella terrigena & $15.5 \pm 0$ & $16 \pm 0$ & $17.5 \pm 0$ & $18.4 \pm 0.1$ & $19.5 \pm 0$ \\
\hline 8. & Fusarium oxysporum & $12.4 \pm 0.1$ & $14 \pm 0$ & $17.4 \pm 0.2$ & $17.5 \pm 0$ & $14 \pm 0$ \\
\hline 9. & Penicillium & $13 \pm 0$ & $16.6 \pm 0.1$ & $18.5 \pm 0$ & $19.6 \pm 0.1$ & $16.5 \pm 0$ \\
\hline 10. & Aspergillus niger & $15.3 \pm 0.1$ & $17 \pm 0$ & $19.2 \pm 0.1$ & $20.5 \pm 0$ & $17.4 \pm 0.2$ \\
\hline
\end{tabular}

*Values are mean of \pm S.D, $n=3$

extract displayed moderate inhibition against Penicillium $(15 \mathrm{~mm})$ and $F$. oxysporum $(14.7 \mathrm{~mm})$. Petroleum ether extract remained sensitive to fungal species possessing minimum inhibition $(13.6 \mathrm{~mm}, 12.6 \mathrm{~mm})$ compared to other extracts.

\section{Microbicidal Efficacy of Biofabricated AgNPs}

In vitro antimicrobial assay of biosynthesized AgNPs using W. somnifera was represented in Table 3. Action of plantmediated AgNPs leads to cell wall and membrane damage, leading to oxidative stress. ${ }^{[46-48]} 400 \mu \mathrm{L}$ of synthesized AgNP was found to be resistant against E. coli $(23 \mathrm{~mm})$, B. cereus $(22.3 \mathrm{~mm})$, and $S$. aureus $(21.3 \mathrm{~mm})$, followed by $300 \mu \mathrm{L}$ of synthesized AgNP $(22.3,21.5$, and $20.5 \mathrm{~mm})$. Das et al. reported the assay of AgNPs against multidrugresistant E. coli and S. aureus and found that ROS generation initiates the bactericidal action. ${ }^{[49,50]} 200 \mu \mathrm{L}$ of AgNP possess moderate inhibition against $K$. pneumoniae $(16.5 \mathrm{~mm})$ and K. terrigena $(16 \mathrm{~mm})$. Anandalakshmi et al. documented the microbicidal action of phytofabricated NPs by Pedalium murex plant against E. coli and $K$. pneumoniae. ${ }^{[51]} 100 \mu \mathrm{L}$ of AgNP displayed a minimum zone of inhibition against $K$. terrigena $(15.5 \mathrm{~mm})$ and M. mucilaginosus $(14.1 \mathrm{~mm})$. Nanoparticles with larger surface areas provide higher interaction and ascendant intracellular penetration. ${ }^{[52]}$

Fungicidal assessment of synthesized AgNP suggest that $400 \mu \mathrm{l}$ acquired maximum inhibition against $A$. niger $(20.5 \mathrm{~mm})$ and Penicillium $(19.6 \mathrm{~mm})$ followed by $300 \mu \mathrm{L}(19.2 \mathrm{~mm}, 18.5 \mathrm{~mm})$. Significant fungicidal effect was observed against fluconazole resistant Candida albicans. ${ }^{[53]} 200 \mu \mathrm{L}$ of synthesized AgNP displayed moderate inhibitory effect against $A$. niger $(17 \mathrm{~mm})$, Penicillium (16.6 $\mathrm{mm})$. The biological mechanisms of silver ions have the capacity to disrupt respiratory system. ${ }^{[54-56]} 100 \mu \mathrm{L}$ of phytosynthesised AgNP possess minimum level of inhibition against Penicillium $(13 \mathrm{~mm})$ and $F$. oxysporum $(12.4 \mathrm{~mm})$. The fungicidal assessment was observed against Curvularia lunata, Bipolaris spicifera, Fusarium oxysporum, and Aspergillus niger, is inhibited by the AgNPs. ${ }^{[57]}$

\section{Conclusion}

Green reactants could accomplish this vital technique by biosynthesis of the AgNPs devoid of using any poisonous substance as bioreductant. Spectroscopic studies indicate the presence of bio-molecules obtained in plant extracts, act as reductant agents for biofabrication of AgNPs.

\section{ACKNOWLEDGMENT}

The author would like to express their sincere gratitude to St. Josephs College, Trichy, and Avinashiligam University, Coimbatore, for providing instrumental techniques.

\section{REFERENCES}

1. Siddiqi KS, Husen A. Recent advances in plant-mediated engineered gold nanoparticles and their application in biological system. J Trace Elem Med Biol. 2017;40:10-23.

2. Gurunathan S, Park JH, Han JW, Kim JH. Comparative assessment of the apoptotic potential of silver nanoparticles synthesized by Bacillus tequilensis and Calocybe indica in MDA-MB-231 human breast cancer cells: Targeting p53 for anticancer therapy. Int J Nanomed. 2015;10:4203-4222.

3. Shah M, Fawcett D, Sharma S, Tripathy S, Poinern G, Shah M, et al. Green synthesis of metallic nanoparticles via biological entities. Materials. 2015;8: 7278-7308.

4. Adil SF, Assal ME, Khan M, Al-Warthan A, Siddiqui MRH, Liz-Marzan LM. Biogenic synthesis of metallic nanoparticles and prospects toward green chemistry. Dalton Trans. 2015;44: 9709-9717.

5. Das B, Dash S, Mandal D, Adhikary J, Chattopadhyay S, Tripathy S, et al. Green-synthesized silver nanoparticles kill virulent multidrugresistant Pseudomonas aeruginosa strains: A mechanistic study. BLDE Univ J Health Sci. 2016;1:89-101

6. Abalkhil TA, Alharbi SA, Salmen SH and Wainwright M. Bactericidal activity of biosynthesized silver nanoparticles against human pathogenic bacteria. Biotechnol Biotechnol Equip. 2017;31:411-417.

7. Alsammarraie FK, Wang W, Zhou P, Mustapha A, Lin M. Green synthesis of silver nanoparticles using turmeric extracts and investigation of their antibacterial activities. Colloids Surf B: Biointerfaces. 2018;171:398-405.

8. Hudecki A, Gola J, Ghavami S, et al. Structure and properties of slow-resorbing nanofibers obtained by (co-axial) electrospinning as tissue scaffolds in regenerative medicine. Peer J. 2017;4125:1-19.

9. Deng H, McShan D, Zhang Y, et al. Mechanistic study of the synergistic antibacterial activity of combined silver nanoparticles and common antibiotics. Environ Sci Technol. 2016;50(16):8840-8848.

10. Veronesi G, Deniaud A, Gallon T, et al.Visualization, quantification and coordination of Ag+ ions released from silver nanoparticles in hepatocytes. Nanoscale. 2016;8(38):17012-17021. 
11. Foldbjerg R, Jiang X, Miclauș T, Chen C, Autrup H, Beer C. Silver nanoparticles-Wolves in sheep's clothing? Toxicol Res. 2015;4: 563-575.

12. Rasheed T, Bilal M, Iqbal HMN, Li C. Green biosynthesis of silver nanoparticles using leaves extract of Artemisia vulgaris and their potential biomedical applications. Colloids Surf B Biointerfaces. 2017;158:408-415.

13. Kokate KC. Practical pharmacognosy. 4th ed., Vallabh Prakashan; Delhi, 1997. p. 218.

14. Hossain MA, Muhammad MD, Charles G, Muhammad I. In vitro total phenolics, flavonoids contents and antioxidant activity of essential oil, various organic extracts from the leaves of tropical medicinal plant Tetrastigma from Sabah. Asian Pac J Trop Med. 2011;4(9): 717-721.

15. Saidulu Ch, Venkateshwar C, Gangadhar Rao S. Preliminary phytochemical study of medicinal plant drug: Withania somnifera L. Biolife. 2014;2(1):306-3012.

16. Ajay M, Jagan MR. A review on the potential therapeutic uses of Withania somnifera. World J Pharmaceutical Sci. 2017;6(7): 846-860.

17. Bhattacharya A, Ramanathan M, Ghosal S, Bhattacharya SK. Effect of Withania somnifera glycowithanolides on iron-induced hepatotoxicity in rats. Phytother Res. 2000;14(7):568-570.

18. Sehgal N, Gupta A, Khader R, Shanker V, Joshi D, Mills JT, et al. Withania somnifera reverses Alzheimer's disease pathology by enhancing low-density lipoprotein receptor-related protein in liver. Proc Nat Acad Sci. 2012;109(9):3510-3515.

19. Bhattacharya A, Ramanathan M, Ghosal S, Bhattacharya SK. Effect of Withania somnifera glycowithanolides on iron-induced hepatotoxicity in rats. Phytother Res. 2000;14(7):568-570.

20. Rajan R, Chandran K, Harper SL, Yun SI, Kalaichelvan PT. Plant extract synthesized silver nanoparticles: An ongoing source of novel biocompatible materials. Ind Crops Prod. 2015;70:356-373.

21. Rauwel P, Rauwel E, Ferdov S, Singh MP. Silver nanoparticles: synthesis, properties, and applications. Adv Mater Sci Eng. 2015;624394:1-2

22. Harborne JB. Phy tochemical methods, a guide to modern techniques of plant analysis. Chapman and Hall Ltd, London; 1973.

23. Stuart BH. Polymer Analysis. John Wiley \& Sons; 2002.

24. Elbeshehy EKF, Elazzazy AM, Aggelis G. Silver nanoparticles synthesis mediated by new isolates of Bacillus sp. nanoparticle characterization and their activity against bean yellow mosaic virus and human pathogens. Front Microbiol. 2015;6:1-13.

25. Verma A, Singh Mehata M. Controllable synthesis of silver nanoparticles using Neem leaves and their antimicrobial activity. J Radiat Res Appl Sci. 2016;9:109-115.

26. Johnson I, Prabu HJ. Green synthesis and characterization of silver nanoparticles by leaf extracts of Cycas circinalis, Ficus amplissima, Commelina benghalensis and Lippia nodiflora. Int Nano Lett. 2015; 5:43-51.

27. Gao Z, Gao F, Shastri KK, Zhang B. Frequency selective propagation of localized spoof surface plasmon in a graded plasmonic resonator chain. Sci Rep. 2016;6:1-6.

28. Anwar MF, Yadav D, Jain S, Kapoor S, Rastogi S, Arora I, Samim M. Size- and shape-dependent clinical and mycological efficacy of silver nanoparticles on dandruff. Int J Nanomed. 2016;11:147-161.

29. Mu H, Tang J, Liu Q, Sun C, Wang T, Duan J. Potent Antibacterial Nanoparticles against Biofilm and Intracellular Bacteria. Sci Rep. 2016;6:1-9.

30. Li S, et al., Green synthesis of silver nanoparticles using Capsicum annuum L. extract. Green Chem. 2007;9(8):852.

31. Suchomel P, Kvitek L, Panacek A, Prucek R, Hrbac J, Vecerova R. Comparative study of antimicrobial activity of $\mathrm{AgBr}$ and $\mathrm{Ag}$ Nanoparticles (NPs). Plos One. 2015; 10(3): e0119202.

32. Guo M, Li W, Yang F, Liu H. Controllable biosynthesis of gold nanoparticles from a Eucommia ulmoides bark aqueous extract. Spectrochim Acta - Part A: Mol Biomol Spectrosc. 2015;142:73-79.

33. Sathishkumar G, Jha PK, Vignesh V, Rajkuberan C, Jeyaraj M, Selvakumar M, et al. Cannonball fruit (Couroupita guianensis, Aubl.) extract mediated synthesis of gold nanoparticles and evaluation of its antioxidant activity. J Mol Liq. 2016;215:229-236.

34. Ramesh PS, Kokila T, Geetha D. Plant mediated green synthesis and antibacterial activity of silver nanoparticles using Emblica officinalis fruit extract. Spectrochim Acta Part A Mol Biomol Spectrosc. 2015;142:339-343.

35. Ahmed S, Ahmad M, Swami BL, Ikram SJ. Green synthesis of silver nanoparticles using Azadirachta indica aqueous leaf extract. Radiat Res Appl Sci. 2016;9(1):1-7.

36. Jyoti K, Baunthiyal M, Singh A. Characterization of silver nanoparticles synthesized using Urtica dioica Linn. leaves and their synergistic effects with antibiotics. J Radiat Res Appl Sci. 2016;9: 217-227.

37. Kumar B, Smita K, Cumbal L, Debut A, Angulo Y. Biofabrication of copper oxide nanoparticles using Andean Blackberry (Rubus glaucus Benth.) fruit and leaf. J Saudi Chem Soc. 2017;21:475-480.

38. Kumari J, Ajeet S. Evaluation of antibacterial activity from phytosynthesized silver nanoparticles against medical devices infected with Staphylococcus sp. J Taibah Univ Med Sci. 2017;12(1): 47-54.

39. Sadeghi B, Gholamhoseinpoor F. A study on the stability and green synthesis of silver nanoparticles using Ziziphora tenuior $(\mathrm{Zt})$ extract at room temperature. Spectrochim Acta Part A: Mol Biomol Spectrosc. 2015; 134: 310-315.

40. Gurunathan S, Jeong JK, Han JW, Zhang XF, Park JH, Kim JH. Multidimensional effects of biologically synthesized silver nanoparticles in Helicobacter pylori, Helicobacter felis, and human lung (L132) and lung carcinoma A549 cells. Nanoscale Res Lett. 2015;10:1-17.

41. Kumar B, Angulo Y, Smita K, Cumbal L, Debut A. Capuli cherrymediated green synthesis of silver nanoparticles under white solar and blue LED light. Particuol. 2016;24:123-128.

42. Kumar B, Smita K, Cumbal L, Angulo Y. Fabrication of silver nanoplates using Nephelium lappaceum(Rambutan) peel: a sustainable approach. J Mol Liq. 2015b;211:476-480.

43. Kumar B, Smita K, Cumbal L, Debut A. Lantana camara berry for the synthesis of silver nanoparticles. Asian Pac J Trop Biomed. 2015d; 5(3):192-195.

44. Ajitha B, Reddy YAK, Reddy PS. Green synthesis and characterization of silver nanoparticles using Lantana camara leaf extract. Mater Sci Eng C. 2015;49:373-381.

45. Mickymaray S, Saleh Al Aboody M, Kumar Rath P, Annamalai P, Nooruddin T. Screening and antibacterial efficacy of selected Indian medicinal plants. Asian Pac J Trop Biomed. 2016;6:185-191.

46. Dakal TC, Kumar A, Majumdar RS and Yadav V. Mechanistic basis of antimicrobial actions of silver nanoparticles. Front Microbiol. 2016;7:1831.

47. Duran N, Duran M, de Jesus MB, Seabra AB, Favaro WJ, Nakazato G. Silver nanoparticles: A new view on mechanistic aspects on antimicrobial activity. Nanomedicine. 2016;12:789-799.

48. Slavin YN, Asnis J, Hafeli UO, Bach H. Metal nanoparticles: understanding the mechanisms behind antibacterial activity. J Nanobiotechnol. 2017;65(15):1-20.

49. Espenti CS, Rao KK, Rao KM. Bio-synthesis and characterization of silver nanoparticles using Terminalia chebula leaf extract and evaluation of its antimicrobial potential. Mater Lett. 2016; 174:129-133.

50. Das B, Dash SK, Mandal D, Ghosh T, Chattopadhyay S, Tripathy S, et al. Green synthesized silver nanoparticles destroy multidrug resistant bacteria via reactive oxygen species mediated membrane damage Arabian J Chem. 2017;10:862-876.

51. .Anandalakshmi K, Venugobal J, Ramasamy V. Characterization of silver nanoparticles by green synthesis method using Pedalium murex leaf extract and their antibacterial activity. Appl Nanosci. 2016;6:399-408.

52. Raza MA, Kanwal Z, Rauf A, Sabri AN, Riaz S, Naseem S. Size and shape dependent antibacterial studies of silver nanoparticles synthesized by wet chemical routes. Nanomater. 2016;6(74): $1-15$. 
53. Kelkawi AHA, Abbasi Kajani A, Bordbar AK. Green synthesis of silver nanoparticles using Mentha pulegium and investigation of their antibacterial, antifungal and anticancer activity IET Nanobiotechnol. 2017;11:370-376.

54. Kim SW, Jung JH, Lamsal K, Kim YS, Min JS, Lee YS. Antifungal effects of silver nanoparticles (AgNPs) against various plant pathogenic fungi. Mycobiol. 2012;40(1):53-58.

55. Kim SW, Kim KS, Lamsal K, Kim YJ, Kim SB, Jung M, Sim SJ, Kim HS, Chang SJ, Kim JK, et al. An in vitro study of the antifungal effect of silver nanoparticles on oak wilt pathogen Raffaelea sp. J Microbiol Biotechnol 2009; 19: 760-764.

56. Min JS, Kim KS, Kim, Jung JH, Lamsal K, Kim SB, Jung M, Lee YS. Effects of colloidal silver nanoparticles on sclerotium-forming phytopathogenic fungi. Plant Pathol J 2009; 25: 376-380.

57. Bhagat M, Anand R, Datt V, Gupta, Arya S. Green synthesis of silver nanoparticles using aqueous extract of Rosa brunonii Lindl and their morphological, biological and photocatalytic characterizations. J Inorg Organomet Polym 2019; 29: 1039.

HOW TO CITE THIS ARTICLE: Anburaj R. Green reactants act as a natural precursor for facile synthesis of nanoparticles using Withania somnifera. Int. J. Pharm. Sci. Drug Res. 2020;12(2):99-106. DOI: 10.25004/IJPSDR.2020.120202 